\title{
An Interactive Educational Mobile Application for System Programming
}

\author{
Sunita M. Dol, Rushikesh Pise, Parmeshwar Reure, \\ Rajkumar Madde, Anirudha Valsangkar \\ Walchand Institute of Technology, Solapur,
}

\begin{abstract}
The purpose of this mobile application proposed for System programming of Computer Science and Engineering is to provide study material, question bank, games like word search puzzle, videos etc. This application also provides answers to the questions in the question bank to help student to clear their doubts in handy manner. It is a type of Modern learning content delivery system. This application will clear all doubts related to System Programming.Students can use this application anywhere, at free of cost. This application can be useful for android based mobile as well as tablets. Students can access all chapters related to the subject System programming. User can check their concept by solving quiz. Student can improve their programming skills by trying Hands-On feature, which is provided in this application. Main vision of this application is to provide a complete set of notes for System programming subject.
\end{abstract}

\section{Keywords}

Android, Eclipse, SDK, Camtasia, System Programming, Games

\section{INTRODUCTION}

In today's scenario, students/learner/geeks are striving to find the right combination to learn new things using technology, use knowledge to manage their learning skill. Android applications are becoming an essential tool for learning, managing course contents, assessing assignments, attempting quizzes and exams, for developing new way of enhancing skills, evaluation and to gain knowledge.

SysPro, an educational based android application is the tool for learning System Programming. This application provides notes, videos, algorithms etc related to system programming.

\section{LITERATURE REVIEW}

SysPro OS Slip: This application provides subject wise practical slips for System Programming and Operating System [12].

Deuter IDE: DeuterIDE's motto is "Light platform, Heavy coding." They definitely achieve this. This app (which is best used on tablets because it excels on a bigger screen) is a feature-heavy IDE with support for over 40 languages. If you're looking for an IDE that can be used to program in a ton of languages, Deuter is right for you[7].

DroidEdit: DroidEdit is an extremely useful source code editor. It utilizes syntax highlighting for multiple languages, including $\mathrm{C} / \mathrm{C}++$, Java, C\#, HTML, Javascript, Python and SQL. Additionally, it has several color themes, search and replace, auto and block indentation, and keyboard shortcuts among many other features[7].
Code Peeker: Code Peeker is an extremely lightweight code reader that allows you to view code really quickly. It supports syntax highlighting for a ton of languages, and when it doesn't support the language it will still open the file as plain text[7].

C4droid: C4droid is a classic $\mathrm{C}$ compiler that you can use on your Android device. It utilizes the gcc compiler, the compiler often used on Unix. C4droid can also compile $\mathrm{C}++$, but you currently need to root your phone to get access to this feature. Overall, C4droid is an effective way to compile your C code on the fly[7].

\section{ARCHITECTURAL DESIGN}

The main menu of proposed architecture is given in figure 1 . There are six chapters of System Programming namely

$\begin{array}{cl}\circ & \text { Language Processors } \\ \circ & \text { Assembler } \\ \circ & \text { Macros and Macro Processors } \\ \circ & \text { Compilers and Interpreters } \\ \circ & \text { Linkers } \\ \bigcirc & \text { Loaders }\end{array}$

For each chapter, notes, question bank, quiz and videos are provided. The games like word search puzzle, word scramble, word matching, cross word puzzle etc are also provided in this application. The example of each game is shown in figure 2 .

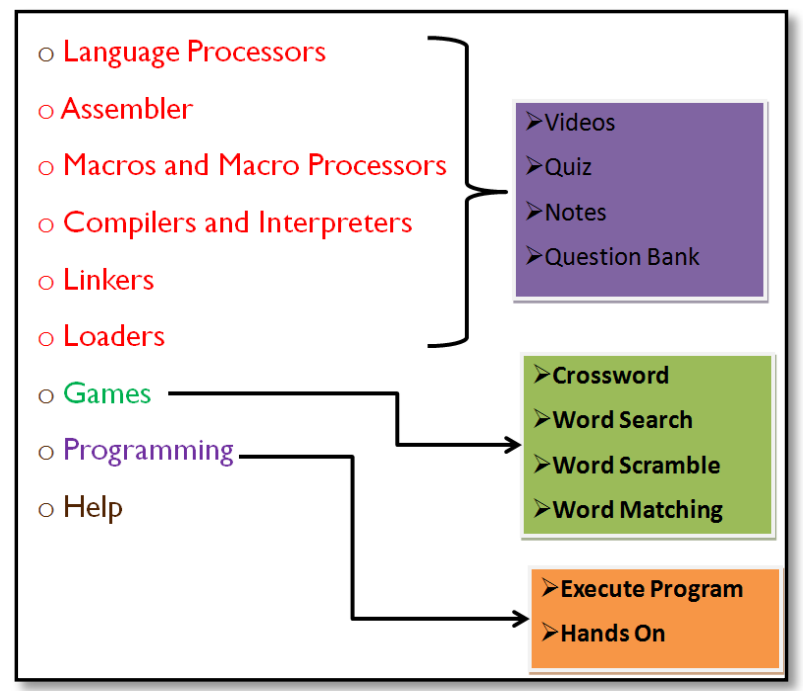

Figure 1: Main menu of proposed application

The next one is Programming option in which simulator is provided to execute the programs of system programs through $\mathrm{C}$ and $\mathrm{C}++$. Last one is Help desk which gives the instruction for how to use an application. 
SYSTEM PROGRAMMING

\begin{tabular}{|l|l|l|l|l|l|l|l|l|l|}
\hline D & T & A & N & A & L & Y & S & I & S \\
\hline F & E & N & D & A & E & N & D & O & C \\
\hline J & Y & Y & B & A & C & K & D & Q & U \\
\hline R & A & S & S & E & M & B & L & E & R \\
\hline M & V & M & A & C & R & O & J & Z & W \\
\hline R & Z & Q & F & R & O & N & T & W & D \\
\hline W & M & I & G & R & A & T & O & R & I \\
\hline M & L & O & A & D & E & R & X & X & G \\
\hline F & S & Y & N & T & H & E & S & I & S \\
\hline T & G & C & O & M & P & I & L & E & R \\
\hline
\end{tabular}

Figure 2a: Word Search Puzzle

\section{SYSTEM PROGRAMMING}

Please unscramble the words below

1. MRBEESSAL

2. ROMAC

3. EROIMCPL

4. EIRNKL

5. DALREO

6. NLISSAAY

7. ESYTSISNH

8. MTIAOINIZTOP

9. ETENPETRIRR

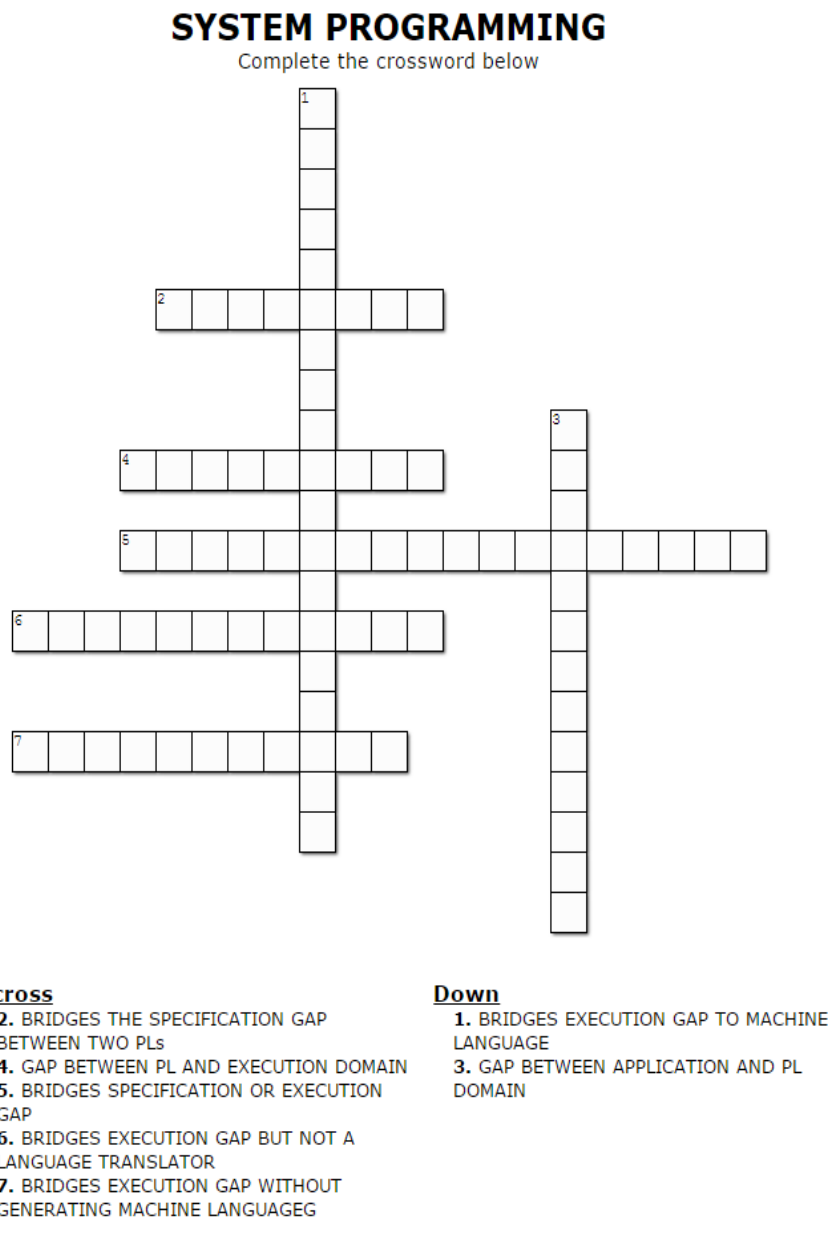

Figure 2c: Cross word puzzle

\section{SYSTEM PROGRAMMING}

Write the letter of the correct match next to each problem.

1. PREPROCESSOR a. BRIDGES SPECIFICATION OR EXECUTION GAP LANGUAGE b. GAP BETWEEN PL AND EXECUTION DOMAIN TRANSLATOR

LANGUAGE C. BRIDGES THE SPECIFICATION GAP BETWEEN

3. PROCESSOR TWO PLS

d. BRIDGES EXECUTION GAP BUT NOT A

4. SEMANTIC LANGUAGE TRANSLATOR

e. BRIDGES EXECUTION GAP WITHOUT INTERPRETER GENERATING MACHINE LANGUAGEG

f. BRIDGES EXECUTION GAP TO MACHINE

6. EXECUTION LANGUAGE

7. MIGRATOR g. GAP BETWEEN APPLICATION AND PL DOMAIN

h. GAP BETWEEN APPLICATION AND EXECUTION

8. SPECIFICATION DOMAIN

Figure 2b: Word Scramble

Figure 2d: Word Matching

Figure 2: Games of proposed application 
The flowchart which is graphical representation of algorithm, workflow or process is shown in figure 3 .

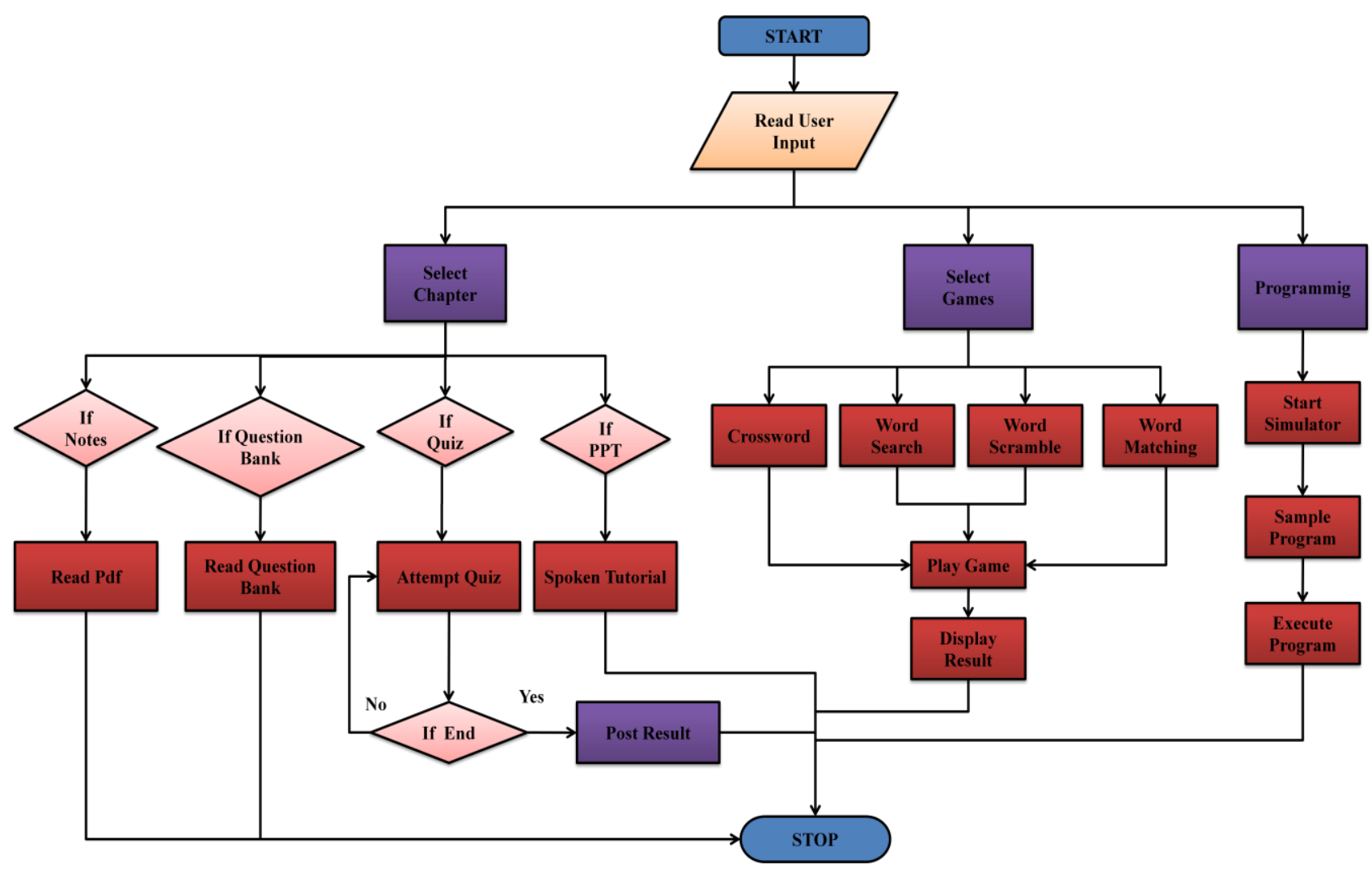

Figure 3: Flowchart for proposed application

First application reads the user input which can be chapter, games and programming related to the subject System programming. If user select chapter of System programming then for each chapter, the user will have four options to choose i.e. notes, question bank, quiz and PowerPoint presentation or videos. If user select games then user can play crosswords or word search or word scramble or word matching game and view the result. After selecting programming option, user can start simulator, use simulator to practise the program and execute the program.

\section{TECHNOLOGY USED}

\subsection{Android}

Android is Operating System based on Linux Kernel specially build for touchscreen mobile devices such as Smartphone's and tablet computers[11]. Android provide open -source platform, this feature has encouraged a large community of developers and enthusiasts to use the open source code for as a foundation for community -driven projects. Android is mostly used mobile operating system. It provides an attractive GUI, and it's totally developer friendly.

\section{SOFTWARE USED \\ 5.1 Android SDK}

Android SDK, which contains multiple files and tools specifically, intended to help you design and develop applications that run on the Android platform [10]. A software is a development kit that enables developers to create applications for the Android platform. The Android SDK includes sample projects with source code, development tools, an emulator, and required libraries to build Android applications. The Android SDK is downloaded in a simple zipped package. The Android SDK is no different from any other SDK in that it contains all the Java code libraries needed to create applications that run specifically on the Android platform.

\subsection{Eclipse}

Eclipse is one of the most fully featured, free, Java IDEs available. Eclipse is also very easy to use, with a minimal learning curve [11]. This makes Eclipse a very attractive IDE for open Java development. It allows Android-specific projects, compile them, and use the Android Emulator to run and debug them. You can still create Android apps in other IDEs, but the Android plug-in for Eclipse creates certain setup elements such as files and compiler settings.

\subsection{Camtasia}

Camtasia is screen recording software that you can use to record your onscreen activity, audio, and web cam video and narrate existing PowerPoint presentations. Using Camtasia you can record, edit, produce and share course content. Camtasia Studio and Camtasia for Mac are software suites for creating video tutorials and presentations directly via screencast, or via a direct recording plug-in to Microsoft PowerPoint.

\section{CONCLUSION}

In general, Android application serves as a means for acquiring the knowledge using the help of technologies e.g. Internet and smart phones over the traditional ways. This Android application process many contents like lecture notes, e-books, algorithms, quizzes and puzzles. Also puzzles will be provided to the student. Students can do some hands on 
International Journal of Computer Applications (0975 - 8887)

Volume 108 - No. 4, December 2014

programming. Android application also serves as the most significant tool for teaching and learning.

\section{REFERENCE}

[1] http://code.google.com/android/documentation.html

[2] http://www.androidjavadoc.com/

[3] http://code.google.com/android/intro/index.html

[4] http://code.google.com/android/intro/tutorial.html

[5] http://groups.google.com/group/android-beginners

[6] http://groups.google.com/group/android-developers
[7] http://android.appstorm.net/roundups/developer/15-appsfor-programming-on-android/

[8] http://en.wikipedia.org/wiki/Camtasia_Studio

[9] http://developer.android.com/

[10] http://en.wikipedia.org/wiki/Eclipse_(software)

[11] http://en.wikipedia.org/wiki/Android_(operating_system)

[12] https://play.google.com/store/apps/detail?id=com.spacec omputer.notesbrowser\&hl=n 